\title{
ARTICLE
}

\section{Chemical state analysis of simulated corium debris by EXAFS}

\author{
Yoshihiro Okamoto, ${ }^{\mathrm{a}, \mathrm{b}^{*}}$ and Masahide Takano ${ }^{\mathrm{a}, \mathrm{b}}$ \\ a Japan Atomic Energy Agency, 2-4 Shirakata, Tokai-mura, Naka-gun, Ibaraki-ken, 319-1195, Japan; ${ }^{b}$ International Research \\ Institute for Nuclear Decommissioning(IRID), 2-23-1, Nishi-Shimbashi, Minato-ku, Tokyo, 105-0003, Japan
}

The chemical state of uranium, zirconium, iron and lanthanide elements in simulated corium debris samples prepared in lab-scale were investigated by synchrotron radiation based extended X-ray absorption fine structure (EXFAS) technique. According to the EXAFS analysis of uranium, their most likely local structure was cubic like fluorite $\mathrm{UO}_{2}$. Exceptionally, pentavalent uranium was observed in the $\mathrm{UO}_{2}-\mathrm{ZrO}_{2}-\mathrm{Fe}_{2} \mathrm{O}_{3}-\mathrm{CaO}$ sample, in which the nearest U-O distance was clearly shorter than those of other samples containing tetravalent uranium. The local structure around zirconium could be classified into cubic, tetragonal and calcia stabilized zirconia with $\mathrm{CaO}$. The oxidation state of iron was divalent for the most samples and a metallic phase was also detected in some of them. The small amount lanthanide elements ( $\mathrm{Nd}$ and $\mathrm{Gd})$ in the simulated debris seem to exist as a solid solution with $\mathrm{UO}_{2}$.

\section{Keywords: simulated corium debris; EXAFS; synchrotron radiation}

\section{Introduction}

The dominant chemical form of uranium in the solidified fuel debris is thought to be $(\mathrm{U}, \mathrm{Zr}) \mathrm{O}_{2 \pm \mathrm{x}}$ solid solution in the case of Fukushima Daiichi NPS accident $[1,2]$. Iron, calcium, and lanthanides derived from the structural materials and fission products are expected to be included as minor soluble components. It is important to clarify the chemical state of each element contained in the fuel debris in order to determine methods of retrieval operation and storage. The EXAFS technique is one of the useful tools since information on each element can be selectively obtained from multicomponent mixtures such as the debris. In the present work, the chemical state of uranium, zirconium, iron and lanthanide elements ( $\mathrm{Nd}$ and $\mathrm{Gd}$ ) in the simulated corium debris samples prepared in lab-scale was evaluated from synchrotron radiation based EXAFS analysis.

\section{Experimental}

\subsection{Simulated corium debris samples}

Twelve simulated corium debris samples containing uranium was prepared in the present work. They are oxide solid solution of uranium, zirconium, iron, gadolinium, neodymium and calcium. The simulated debris samples used in the present work are summarized in Figure 1. The samples $\mathrm{UO}_{2}, \mathrm{U}_{3} \mathrm{O}_{8}$ and three kinds of $\mathrm{UO}_{2}-\mathrm{ZrO}_{2}$ solid solution (A1-A5) can be regarded as

*Corresponding author. Email: yokamoto@spring8.or.jp fundamental materials. In addition, $\mathrm{Fe}$ and $\mathrm{Ca}$ were added assuming the reaction with reactor pressure vessel and concrete material. As fission product component, $\mathrm{Gd}$ and $\mathrm{Nd}$ were used in the present work. The samples adding $\mathrm{Fe}, \mathrm{Zr}$ and $\mathrm{Ca}$ to $\mathrm{UO}_{2}$ are marked as $\mathrm{B} 1-\mathrm{B} 5$. The samples adding $\mathrm{Gd}$ and $\mathrm{Nd}$ to $\mathrm{UO}_{2}, \mathrm{~B} 3$ and $\mathrm{B} 4$ and some related samples are defined as $\mathrm{C} 1-\mathrm{C} 7$. The samples were prepared by sintering of the mixture pellet of each oxide powder $\left(\mathrm{UO}_{2}, \mathrm{ZrO}_{2}, \mathrm{Fe}_{2} \mathrm{O}_{3}, \mathrm{CaO}, \mathrm{Gd}_{2} \mathrm{O}_{3}\right.$ and $\left.\mathrm{Nd}_{2} \mathrm{O}_{3}\right)$ at $1873-1973 \mathrm{~K}$ for 6 hours in $\mathrm{Ar}$ gas (10-30ppm purity) flow. The powder sample taken from the pellet was used in the EXAFS measurement. Three samples; monoclinic and tetragonal $\mathrm{ZrO}_{2}$ and calcia stabilized zirconia $\mathrm{Zr}_{0.84} \mathrm{Ca}_{0.16} \mathrm{O}_{1.84}$ were used as standard materials.

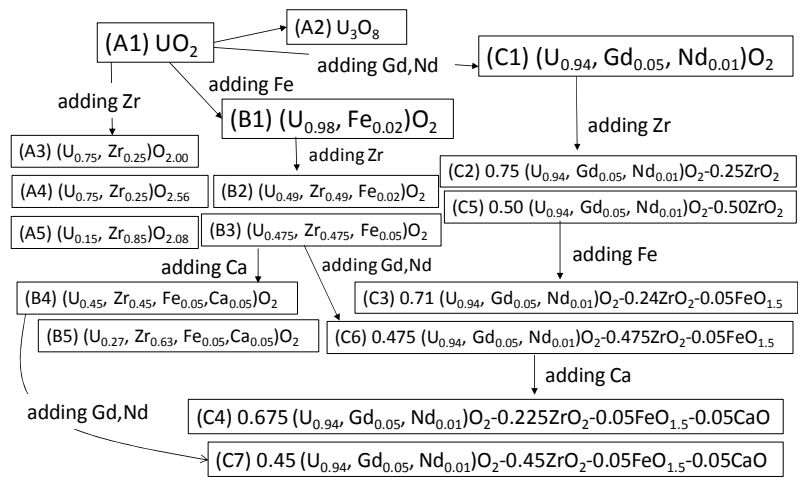

Figure 1. Tree diagram of the simulated corium debris samples used in the EXAFS analysis.

\subsection{EXAFS analysis}

The XAFS measurement was performed at the 
BL-27B station of KEK, Tsukuba, Japan. X-ray beam monochromatized by $\mathrm{Si}(111)$ double crystals is available in the beamline. The XAFS data of the $\mathrm{U} \mathrm{L}_{3}$-edge, $\mathrm{Zr}$

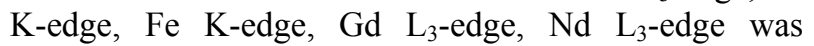
obtained using transmission and fluoresecne mode. The XAFS data was analyzed by WinXAS Ver.3.2[3] in order to obtain EXAFS function $\mathrm{k}^{3} \chi(\mathrm{k})$ and Fourier transform magnitude $|\mathrm{FT}|$. The structural parameter like coordination number and interatomic distance was obtained by the curve fitting procedure in the WinXAS. The correction parameter required in the fitting analysis; phase shift and backscattering amplitude was obtained from the XAFS simulation software FEFF Ver.8.4 [4].

In the persent work, we have to pay attention to the limitation in the EXAFS analysis of mutiphase sample. According to the phase diagram of $\mathrm{UO}_{2}-\mathrm{ZrO}_{2}$ system $[5,6]$, the sample are unlikely to be single phase solid solution. In most cases, $\mathrm{UO}_{2}-\mathrm{ZrO}_{2}$ solid solutions consist of at least two phases; typically uranium rich and zirconium rich phases. Then it is natural to consider that the EXAFS of uranium reflects signals from uranium rich phase of the sample.

\section{Results and discussion}

\subsection{Adding $\mathrm{Zr}$ to $\mathrm{UO}_{2}$ and $\mathrm{O} / \mathrm{M}$ dependence}

The $\mathrm{U} \mathrm{L}_{3}$-edge EXAFS functions and thier FT magnitudes of the samples A3-A5 are shown in Figure 2, together with those of $\mathrm{UO}_{2}(\mathrm{~A} 1)$ and $\mathrm{U}_{3} \mathrm{O}_{8}(\mathrm{~A} 2)$. The EXAFS results of the A3 sample $\left(\mathrm{U}_{0.75} \mathrm{Zr}_{0.25}\right) \mathrm{O}_{2.00}$ are close to those of the $\mathrm{UO}_{2}$ fluorite structure, though the amplitude in $\mathrm{k}$-space and the peak height in $\mathrm{R}$-space are slightly lower than those of the $\mathrm{A} 1$ sample $\mathrm{UO}_{2}$. It can be considered that the cubic structure like $\mathrm{UO}_{2}$ was kept in the A3 sample. The A4 sample $\left(\mathrm{U}_{0.75} \mathrm{Zr}_{0.25}\right) \mathrm{O}_{2.56}$ and the A5 sample $\left(\mathrm{U}_{0.15} \mathrm{Zr}_{0.85}\right) \mathrm{O}_{2.08}$ resulted in slightly shorter U-O distance in the FT magnitude as shown in the Figure 1. The fitting values $2.18 \AA$ for the A4 sample and $2.22 \AA$ for the A5 sample are clearly shorter than $2.34 \AA$ for the A1 sample $\left(\mathrm{UO}_{2}\right)$ but are close to $2.22 \AA$ for the $\mathrm{A} 2$ sample $\left(\mathrm{U}_{3} \mathrm{O}_{8}\right)$. It means that uranium in the A4 and A5 samples is not tetravalent. The 2nd peak position of the A4 sample is close to that of $\mathrm{U}_{3} \mathrm{O}_{8}$. On the other hand, the 2nd peak of the A5 sample was very weak and its position was shorter than that of $\mathrm{U}_{3} \mathrm{O}_{8}$.

The $\mathrm{Zr}$ K-edge EXAFS functions and thier FT magnitudes of the samples A3-A5 are shown in Figure 3, together with those of tetragonal and momoclinic $\mathrm{ZrO}_{2}$ and calcia stabilized zirconia (CSZ). The EXAFS function of the A3 sample is not in agreement with that of monocllinic $\mathrm{ZrO}_{2}$ [7] as can be seen in the Figure 3 . According to the curve fitting analysis of the 1 st peak, the nearest $\mathrm{Zr}-\mathrm{O}$ distance was $2.18 \AA$ for the $\mathrm{A} 3$ sample. This value is sllightly longer than those of tetragonal $\mathrm{ZrO}_{2}(2.065 \AA)$ [8] and CSZ (2.12 $\AA$ ) [9]. Instead it is close to $2.20 \AA$ for unstable cubic $\mathrm{ZrO}_{2}$ [7]. The 2nd peak of the A3 sample was not singlet but split into three correlations. We can easily notice that it is relatively close to the corresponding function of the $\mathrm{U} \mathrm{L}_{3}$-edge FT data shown in the Figure 2. Therefore it suggests that the local structure around $\mathrm{Zr}$ in the A3 sample is cubic. The EXAFS results of the A4 sample are in good agreement with those of CSZ. The EXAFS function of the A5 sample showed very small oscillation. The small oscillation in the EXAFS function may be assigned to disordered strucrure, multiphase effect or the self absorption effect. Threfore, it is difficult to determine the local structrure, though the FT magnitude showed the peak profile similar to CSZ.
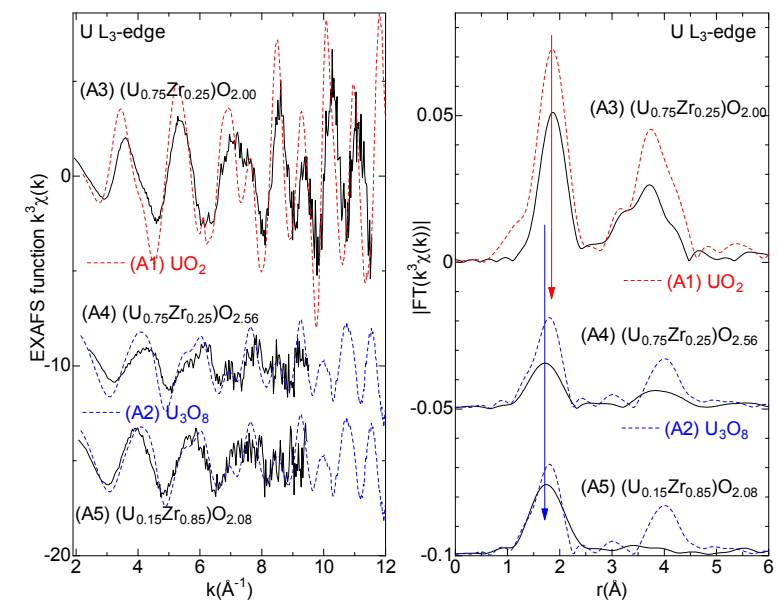

Figure 2. $\mathrm{U} \mathrm{L}_{3}$-edge EXAFS functions and FT magnitude functions of the A1-A5 samples.
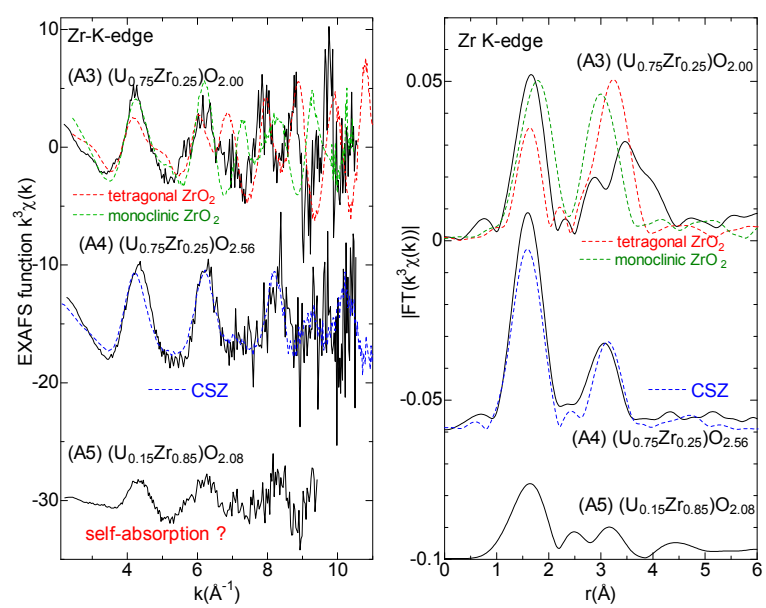

Figure 3. Zr K-edge EXAFS functions and FT magnitude functions of the A3-A5 samples.

\subsection{Adding $\mathrm{Fe}, \mathrm{Zr}$ and $\mathrm{Ca}$ to $\mathrm{UO}_{2}$}

In the next step, we made an investigation into the effect of additional elements ( $\mathrm{Zr}$ and $\mathrm{Ca}$ ). The $\mathrm{U} \mathrm{L}_{3}$-edge EXAFS functions and thier FT magnitudes of the samples B1-B5 are shown in Figure 4, together with those of $\mathrm{UO}_{2}(\mathrm{~A} 1)$ and the sample $\mathrm{A} 3$. In all the samples, the EXAFS results are similar to those of the sample A3 $\left(\mathrm{U}_{0.75} \mathrm{Zr}_{0.25}\right) \mathrm{O}_{2.00}$. It means that the local structure of them is basically cubic. The nearest U-O distance obtained from the curve fitting analysis ranged from 2.32 to $2.35 \AA$ for the B1, B2, B3 and B4 samples. 
Only the B5 sample showed different U-O distance, 2.27 $\AA$. It is shorter than that of tetravalent $\mathrm{UO}_{2}$ but longer than hexavalent $\mathrm{UO}_{3}[10]$. It suggests that the oxidation state of uranium is pentavalent, since single phase state was confirmed for the sample B5 from SEM/EDX and $\mathrm{X}$-ray diffraction analyses.

The $\mathrm{Zr}$ K-edge EXAFS functions and thier FT magnitudes of the samples B2-B5 are shown in Figure 5. The obtained EXAFS results are in good agreement with either of the two results of the A3 sample and CSZ. It can be clear that the local structure around zirconium is tetragonal with iron oxide and CSZ with calcium.
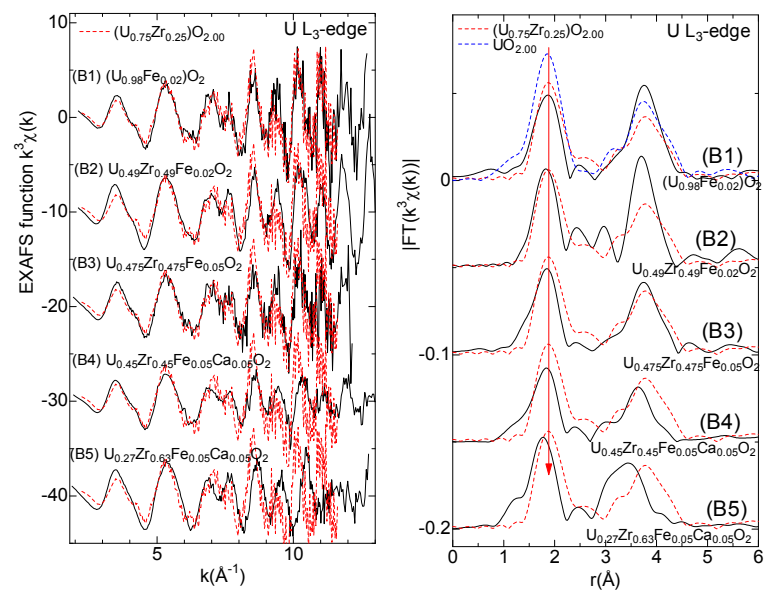

Figure 4. $\mathrm{U} \mathrm{L}_{3}$-edge EXAFS functions and FT magnitude functions of the B1-B5 samples.
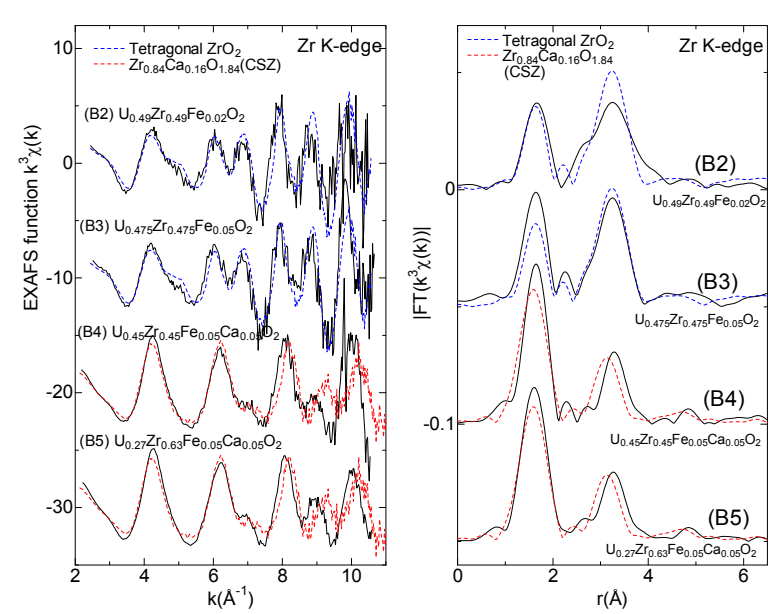

Figure 5. Zr K-edge EXAFS functions and FT magnitude functions of the B2-B5 samples.

The normalized Fe K-edge XANES spectra and the FT magnitudes of the samples B1-B5 are shown in Figure 6, together with those of iron standard samples. In comparison with spectra of divalent $\mathrm{FeO}$ and trivalent $\mathrm{Fe}_{2} \mathrm{O}_{3}$, the oxidation state of iron in all the samples is thought to be mainly divalent. The 1 st peak can be assigned to the $\mathrm{Fe}-\mathrm{O}$ of divalent $\mathrm{FeO}$ from the curve fitting analysis. The 2 nd peak which is observed near the 1 st peak in the FT magnitudes of the sample B1 and B2 suggests that these samples are a mixture with iron metal, sinde its distance $(2.45 \AA)$ is shorter than $\mathrm{Fe}-\mathrm{Fe}$ separation $(3.05 \AA)$ in $\mathrm{FeO}$.
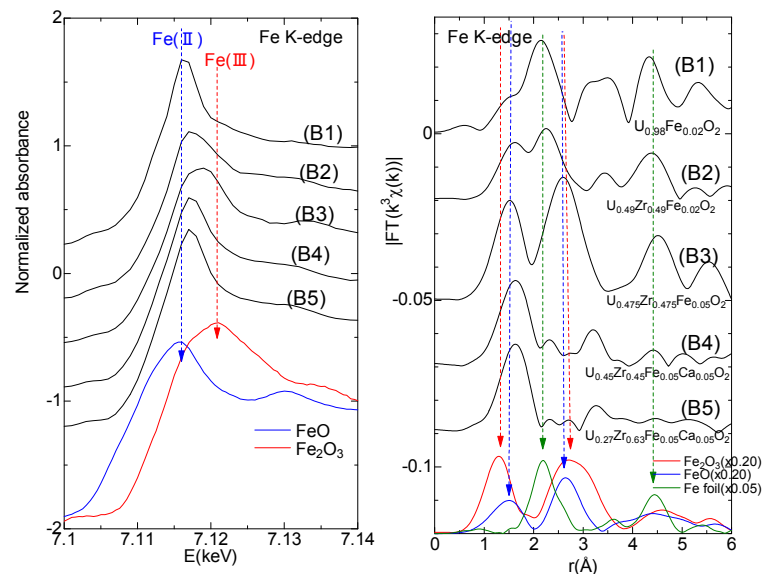

Figure 6. Fe K-edge normalized XANES spectra and FT magnitude functions of the B1-B5 samples.

\subsection{Adding lanthanides, $\mathrm{Zr}$, Fe and $\mathrm{Ca}$ to $\mathrm{UO}_{2}$}

The $\mathrm{U} \mathrm{L}_{3}$-edge and $\mathrm{Zr} \mathrm{K}$-edge EXAFS functions of the samples C1-C7 samples are shown in Figure 7. The function of the B1 sample is in good agreement with that of fluorite $\mathrm{UO}_{2}$. It is considered that the cubic structure observed in the sample A3 $\left(\mathrm{U}_{0.75} \mathrm{Zr}_{0.25}\right) \mathrm{O}_{2.00}$ is prredominant in all other samples. The $\mathrm{Zr} \mathrm{K}$-edge EXAFS functions in the Figure 7 could be classified into three types. The samples $\mathrm{C} 2$ and $\mathrm{C} 5$, in which $\mathrm{UO}_{2}$, $\mathrm{ZrO}_{2}$ and lanthanide oxides are contaiend, resulted in the cubic structure like the sample A3. They changed to tetragonal structure by adding iron oxide as seen in the samples C3 and C6. By adding calcium, CSZ structure was observed in the samples $\mathrm{C} 4$ and $\mathrm{C} 7$. These results are compatible with conclusion in the preceding section.
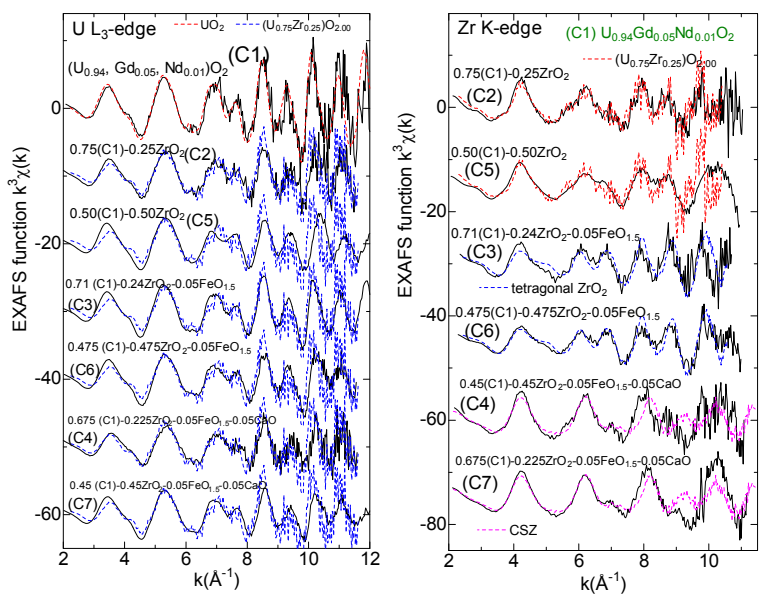

Figure 7. $\mathrm{U} \mathrm{L}_{3}$-edge and $\mathrm{Zr} \mathrm{K}$-edge EXAFS functions of the C1-C7 samples.

The $\mathrm{Gd} \mathrm{L}_{3}$-edge and $\mathrm{Nd}_{3}$-edge EXAFS functions of the sample $\mathrm{C} 1-\mathrm{C} 7$ and the FT magnitudes of the $\mathrm{C} 1$ sample are shown in Figure 8. A significant change was not observed in the $\mathrm{Gd} \mathrm{L}_{3}$-edge EXAFS functions and all were almost the same. It is not in agreement with that of pure $\mathrm{Gd}_{2} \mathrm{O}_{3}$. Similar results were obtained in the $\mathrm{Nd}$ $\mathrm{L}_{3}$-edge results. It is well known that gadolinium makes 
solid solution with $\mathrm{UO}_{2}$ [11]. The FT magnitudes of the sample $\mathrm{C} 1$ is relatively close to that of $\mathrm{UO}_{2}(\mathrm{~A} 1)$. As the results of curve fitting analysis, the 1 st $\mathrm{Gd}-\mathrm{O}$ and $\mathrm{Nd}-\mathrm{O}$ distances were $2.41 \AA$ and $2.43 \AA$, respectively. Their coordination number was close to 8 . It can be suggested that these lanthanide elements exists as solid solution with $\mathrm{UO}_{2}$ in the samples $\mathrm{C} 1-\mathrm{C} 7$.
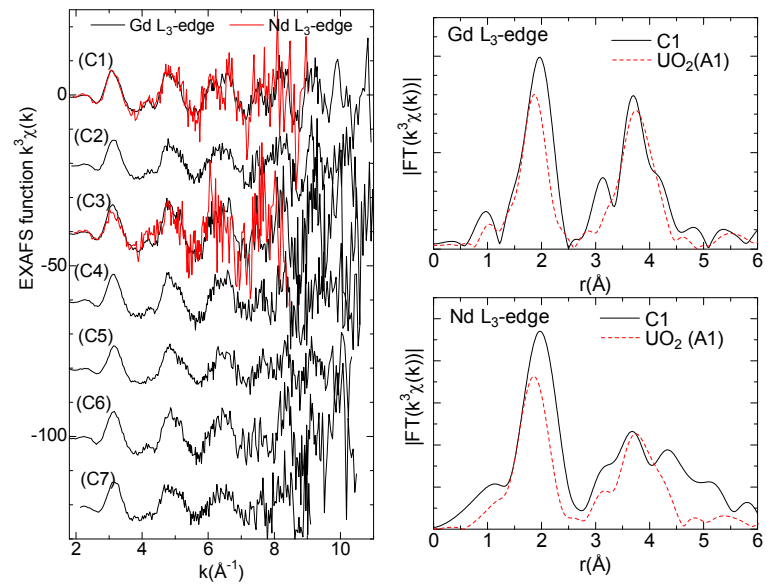

Figure 8. $\mathrm{Gd} \mathrm{L}_{3}$-edge and $\mathrm{Nd} \mathrm{L}_{3}$-edge EXAFS functions of the C1-C7 samples and FT magnitudes of the $\mathrm{C} 1$ sample.

\section{Conclusion}

The chemical state of uranium, zirconium, iron and lanthanides in the simulated corium debris samples were evaluated from the EXAFS analysis (comparison with standard materials and the curve fitting analysis). The results listed in Table $\mathbf{1}$ are summarized as follows,

Table 1. Chemical state of uranium, zirconium and iron in the simulated corium debris samples evaluated by the EXAFS analysis ( $X$; not contained, $\bigcirc$ :contained).

\begin{tabular}{|c|c|c|c|c|}
\hline & $\mathrm{U}$ & $\mathrm{Zr}$ & $\mathrm{Fe}$ & $\mathrm{Ca}$ \\
\hline $\mathrm{A} 3$ & cubic(IV) & cubic & $\times$ & $\times$ \\
\hline $\mathrm{A} 4$ & $\mathrm{U}_{3} \mathrm{O}_{8}$ & $\mathrm{CSZ}$ & $\times$ & $\times$ \\
\hline A5 & $\mathrm{U}_{3} \mathrm{O}_{8}$ ? & unsolved & $\times$ & $\times$ \\
\hline B1 & cubic(IV) & $\times$ & metal, $\mathrm{Fe}(\mathrm{II})$ & $\times$ \\
\hline B2 & cubic(IV) & tetragonal & metal, Fe(II) & $\times$ \\
\hline B3 & cubic(IV) & tetragonal & $\mathrm{Fe}(\mathrm{II})$ & $\times$ \\
\hline B4 & cubic(IV) & $\mathrm{CSZ}$ & $\mathrm{Fe}(\mathrm{II})$ & $\bigcirc$ \\
\hline B5 & cubic(V) & $\mathrm{CSZ}$ & $\mathrm{Fe}(\mathrm{II})$ & $\bigcirc$ \\
\hline C1 & fluorite(IV & $\times$ & $\times$ & $\times$ \\
\hline C2 & cubic(IV) & cubic & $\times$ & $\times$ \\
\hline C3 & cubic(IV) & tetragonal & $\mathrm{Fe}(\mathrm{II})$ & $\times$ \\
\hline C4 & cubic(IV) & CSZ & $\mathrm{Fe}(\mathrm{II})$ & $\bigcirc$ \\
\hline C5 & cubic(IV) & cubic & $\times$ & $\times$ \\
\hline C6 & cubic(IV) & tetragonal & $\mathrm{Fe}(\mathrm{II})$ & $\times$ \\
\hline C7 & cubic(IV) & CSZ & $\mathrm{Fe}(\mathrm{II})$ & $\bigcirc$ \\
\hline
\end{tabular}

(1)The chemical state of uranium was mainly tetravalent with the cubic structure.

(2)In the sample B5 $\left(\mathrm{U}_{0.25} \mathrm{Zr}_{0.63} \mathrm{Fe}_{0.05} \mathrm{Ca}_{0.05}\right) \mathrm{O}_{2}$, the oxidation state of uranium was pentavalent.

(3)The oxidation state of iron was mainly divalent in the most samples. Metallic component was also observed in the samples B1 and B2.

(4)The chemical form of zirconium was classified into the cubic equivalent to uranium, tetragonal and CSZ. The tetragonal form was found in the samples containing iron and CSZ was observed in the samples with calcium (except for the A4 sample in which calcium is not contained).

(5)The EXAFS results of $\mathrm{Gd}$ and $\mathrm{Nd}$ in the simulated debris samples suggests cubic structure similar to $\mathrm{UO}_{2}$. It can be concluded that chemical state of uranium does not change drastically by the mixing, though pentavalent uranium was observed. On the other hand, the local structure around zirconium changes by mixing with iron and calcium.

\section{Acknowledgements}

This work was carried out under the "Project of Decommissioning and Contaminated Water Management under FY2014 Supplementary Budget" subsidized to IRID. The EXAFS measurement was performed under KEK proposal No. $2015 \mathrm{G} 084$.

\section{References}

[1] M. Takano and T. Nishi, High temperature reaction between sea salt deposit and $(\mathrm{U}, \mathrm{Zr}) \mathrm{O}_{2}$ simulated corium debris, J. Nucl. Mater. 443 (2013), pp. 32-39.

[2] P.D. Bottomley, M. Murray-Farthing, T. Wiss, B. Cremer, C. Boshoven, P. Lajarge and V. Rondinella, Investigation of the melting behavior of the U-Zr-Fe-O system, J. Nucl. Sci. Tech. 52 (2015), pp. 1217-1225.

[3] T. Ressler, WinXAS: A program for X-ray absorption spectroscopy data analysis under MS-Windows, J. Synchrotron Rad. 5 (1998), pp. 118-122.

[4] A.L. Ankudinov, B. Ravel, J.J. Rehr and S.D. Conradson, Real-space multiple-scattering calculation and interpretation of X-ray absorption near edge structure, Phys. Rev. B, 58 (1998), pp. 7565-7576.

[5] P.E. Evans, The system $\mathrm{UO}_{2}-\mathrm{ZrO}_{2}$, J. Amer. Ceram. Soc. 43 (1960), pp. 443-447.

[6] I. Cohen and B.E. Schaner, A metallographic and X-ray study of the $\mathrm{UO}_{2}-\mathrm{ZrO}_{2}$ system, J. Nucl. Mater. 9 (1963), pp. 18-52.

[7] J.D. McCullough and K.N. Trueblood, The crystal structure of baddeleyite (Monoclinic $\mathrm{ZrO}_{2}$ ), Acta. Cryst. 12 (1959), pp. 507-511.

[8] G. Teufer, The crystal structure of tetragonal $\mathrm{ZrO}_{2}$, Acta. Cryst, 15 (1962), p. 1187.

[9] L.M. Moroney and D.E. Sayers, The defect structure of calcia stabilized zirconia, J. Phys. Coll. Suppl. 12 (1986), pp. C8-725-728.

[10]E. Wait, A cubic form of uranium trioxide, J. Inorg. Nucl. Chem. 1 (1955), pp. 309-312.

[11]S. Fukushima, T. Ohmichi, A. Maeda and H. Watanabe, J. Nucl. Mater. 105 (1982), pp. 201-210. 